Indonesian Journal of Elementary Education

Vol. 1, No.2, Juli 2021

E-ISSN: 2722-6689

http://jurnal.umt.ac.id/index.php/lJOEE

\title{
ANALISIS PERAN GURU DALAM MENUMBUHKAN SIKAP CINTA TANAH AIR PADA MATA PELAJARAN PKN SISWA KELAS III SDN TANGERANG 15
}

\author{
${ }^{1}$ Fiki nurul latifah, ${ }^{2}$ Imam Muttaqijn, ${ }^{3}$ Nur Latifah \\ Universitas Muhammadiyah Tangerang, Jl. Perintis Kemerdekaan 1 No. 33 \\ Cikokol Tangerang \\ e-mail : fikinurul08@gmail.com, nurlatifahv4@gmail.com
}

\begin{abstract}
Abstrak
Peran guru adalah membantu siswa dalam mengembangkan keterampilan baik dalam perencanaan maupun pelaksanaan kurikulum. Tujuan penelitian ini untuk mengetahui peran guru dalam menumbuhkan sikap cinta tanah air melalui mata pelajaran PKN siswa kelas III SDN Tangerang 15. Sampel penelitian diambil melalui angket google form kepada guru kelas III SDN Tangerang 15. Partisipan diambil dari guru kelas sejumlah 2 guru terdiri dari guru kelas III menggunakan soal bentuk essay yang dikembangkan berdasarkan indikator peran guru menurut P. Ratu Ile Tokan. Dalam penelitian ini mengunakan metode kualitatif deskriptif. Pengumpulan data di lakukan melalui metode observasi, wawancara dan dokumentasi. Metode deskriptif adalah metode yang menjelaskan atau mendeskripsikan suatu fakta, data, dan objek penelitian secara sistematis dan sesuai dengan situasi alamiah. hasil penelitian ini menunjukan dengan memberikan contoh yang baik dan mencintai tanah air dalam kehidupan sehari-hari dapat memberikan sikap cinta tanah air. Guru selalu mengingatkan bersikap jujur dan menghargai berbedaan, toleransi dan displin di sekolah maupun diluar sekolah. Penanaman cinta tanah air dilakukan di sekolah yang lebih efektif karena dapat membentuk jiwa serta semangat bagi siswa yang akan menentukan masa depannya. Rasa cinta tanah air merupakan memperkuat persatuan dan kesatuan bangsa dalam kehidupan sehari-hari seperti dalam lingkungan sekolah, keluarga maupun masyarakat.
\end{abstract}

Kata kunci: sikap cinta tanah air, pembelajaran pkn, sekolah dasar.

\begin{abstract}
The teacher's role is to assist students in developing skills both in planning and implementing curriculum. The purpose of this study was to determine the teacher's role in fostering an attitude of love for the homeland through PKN subjects for third grade students at SDN Tangerang 15. The research sample was taken through a google form questionnaire to third grade teachers at SDN Tangerang 15. Participants were taken from class teachers of 2 teachers consisting of teachers class III used essay questions which were developed based on teacher role indicators according to P. Ratu Ile Tokan. In this study using descriptive qualitative methods. Data collection is done through the methods of observation, interviews and documentation. Descriptive method is a method that explains or describes a fact, data, and object of research systematically and in accordance with natural situations. The results of this study show that by giving a good example and loving the homeland in daily life can provide an attitude of love for the homeland. Teachers always remind to be honest and respect differences, tolerance and discipline at school and outside school. Planting love for the homeland is carried out in schools that are more effective because they can form the soul and spirit of students who will determine their future. The love for the homeland is to strengthen the unity and integrity of the nation in everyday life such as in the school, family and community environment.
\end{abstract}

Keyword: patriotism, pkn learning, elementary school. 
Indonesian Journal of Elementary Education

Vol. 1, No.2, Juli 2021

E-ISSN: 2722-6689

http://jurnal.umt.ac.id/index.php/IJOEE

\section{PENDAHULUAN}

Berbagai rintangan dan hambatan adalah tantangan bagi seorang guru dalam mendidik siswa dilingkungan sekolah. Guru adalah seorang pendidik dan pengajar yang berperan penting untuk dapat memberikan pembelajaran di kelas dengan komunikatif. Seorang guru harus memberikan contoh sikap yang baik agar bisa ditiru oleh siswa dan dapat menjadi cerminan di masyarakat. Didalam Undang - Undang Republik Indonesia Nomor 14 Tahun 2005 tentang guru dan dosen pasal 1 "guru adalah pendidik professional dengan tugas utama mendidik, mengajar, membimbing, mengarahkan, melatih, menilai dan mengevaluasi peserta didik pada pendidikan anak usia dini dijalur pendidikan formal, pendidikan dasar dan pendidikan menengah”. Berdasarkan undang - undang tersebut tugas guru memberikan arahan agar tujuan dapat tercapai yaitu mampu mencerdaskan bangsa.

Menurut Suparno (2004) adalah posisi dan peran guru berhadapan langsung dengan siswa melalui proses pembelajran di sekolah, maka upaya meningkatan kualitas pembelajaran sebagian besar menjadi tugas dan tanggung jawab guru (Ismawati, 2015:878). Jadi guru bertanggung jawab penuh atas kualitas dan juga proses pembelajaran yang ada di sekolah. Sedangkan menurut Darmadi (2010) guru adalah kondisi yang diposisikan sebagai garda terdepan dan posisi sentral di dalam proses pembelajaran (Ismawati, 2015:879). Guru merupakan orang yang serius dalam membantu dalam pencapaian siswa di sekolah. Sedangkan menurut Kusnandar (2007) profesional guru adalah guru yang mengenal tentang dirinya, yaitu panggilan hati untuk mendampingi peserta didik dalam belajar (Diana Sari, 2017:67). Menjadi guru harus bisa membimbing, membina dan juga mengayomi kemampuan siswa.

Berdasarkan referensi tersebut maka dapat disimpulkan bahwa peran guru adalah seseorang yang professional dan bertanggung jawab yang memiliki peran penting dalam pelaksanaan, pertumbuhan dan pengembangan kurikulum di sekolah, guru memiliki tugas yang besar untuk dapat memberikan pendidikan yang baik bagi siswa. Jadi dengan adanya peran guru mempersiapkan siswa menjadi invidual yang mandiri dan juga menjadikan siswa mewujudkan sikap cinta tanah air dan ilmu pengetahuan dengan baik. 
Indonesian Journal of Elementary Education

Vol. 1, No.2, Juli 2021

E-ISSN: 2722-6689

http://jurnal.umt.ac.id/index.php/lJOEE

Bahwa pendidikan cinta tanah air menjadikan siswa untuk memahami unsur nasional serta dapat melestarikan nilai - nilai kebudayaan bangsa Indonesia. Jadi sikap cinta tanah air itu penting dimiliki setiap individu yaitu dengan membela dan melindungi tanah air dan menunjukan kepedulian serta penghargaan terhadap bangsa. Menanamkan sikap cinta tanah air bisa dilakukan dengan menumbuhkan rasa bangga terhadap tanah air di dalam pendidikan. Menurut Karnadi (2007) bahwa, cinta tanah air merupakan pola pikir, pola sikap, dan pola perilaku yang menunjukan kesetiaan, kepedulian, dan penghargaan yang tinggi terhadap bangsa dan negara (Komalasari and Wihaskoro, 2018:132). Cinta tanah air rasa peduli terhadap sikap dan perilaku yang di tunjukan untuk bangsa. Sedangkan Winarno dan suhartatik mengatakan, bahwa cinta pada bangsa dan tanah air artinya setia pada bangsa dan negara indonesia dengan berbuat sesuatu yang baik ditujukan untuk kemajuan bangsa dan kemajuan masyarakat Indonesia (Kusuma, 2017:2). Rasa cinta tanah air adalah setia dan bersikap jujur untuk menjadikan masyarakat Indonesia yang lebih baik. Sedangkan menurut Ulifah and Suwansa (2017) berpendapat, rasa cinta tanah air merupakan rasa kebanggaan, memiliki, menghormati dan loyalitas pada negara tempat ia tinggal (871-886). Jadi rasa cinta tanah air adalah sikap cinta tanaha air yang ditanamkan pada setiap individu yang tercermin dalam sikap rela berkorban.

Berdasarkan referensi tersebut bahwa cinta tanah air itu penting karena dengan cinta tanah air salah satu mencintai adat dan budaya terbukti dengan minat pembelajaran PKN yang memberikan nilai - nilai cinta tanah air misalnya dalam menggunakan bahasa Indonesia dengan baik, memberikan sikap dan perilaku yang menghargai dan mencintai keberagaman. Untuk itu perlu adanya penanaman sikap cinta tanah air menurut Polignano (2019) menjelaskan, sikap cinta tanah air perlu ditanamkan sejak usia dini, agar sebagai generasi penerus bangsa dapat mewujudkan sikap dan tingkah laku yang bermanfaat bagi kepentingan masyarakat dan menghindari penyimpangan-penyimpangan sosial yang dapat merusak norma-norma dan nilai-nilai kebudayaan Indonesia (h.29). karena peyimpangan dapat merugikan diri sendiri tapi juga dapat merugikan masyarakat bahkan negara. Dengan mewujudkan sikap cinta tanah air dapat memberikan perilaku yang menunjukan penghargaan, kepedulian yang memberikan semangat dan rela berkorban bagi bangsa. 
Indonesian Journal of Elementary Education

Vol. 1, No.2, Juli 2021

E-ISSN: 2722-6689

http://jurnal.umt.ac.id/index.php/lJOEE

Sikap cinta tanah air dapat dituangkan dengan pembelajaran pkn dalam kehidupan sehari - hari, pembelajaran PKN adalah mata pelajaran yang berfokus kepada siswa agar dapat menjadi warga negara yang memiliki sikap pancasila. Tujuan pembelajaran PKN untuk meningkatkan kepribadian yang mandiri dan bertanggung jawab serta sehat jasmani maupun rohani. Menurut Ruminiati (2008), Pendidikan kewarganegaraan (PKn) merupakan mata pelajaran sosial yang bertujuan untuk membentuk atau membina warganegara yang baik yaitu warganegara yang tahu, mau dan mampu berbuat baik (Masoyang, Saneba, and Palimbong, 2014:131). Pendidikan kewarganegaraan menjadikan siswa memiliki pengetahuan tentang bela negara. Sedangkan menurut Djahiri (1997) menjelaskan, Pendidikan kewarganegaraan adalah mata pelajaran yang digunakan sebagai wahana untuk mengembangkan dan melestarikan nilai luhur dan moral yang berakar pada budaya bangsa Indonesia yang diharapkan dapat diwujudkan dalam bentuk perilaku dalam kehidupan sehari-hari peserta didik, baik sebagai individu, anggota masyarakat, warga negara maupun makhluk ciptaan Tuhan Yang Maha Esa (Masoyang et al. 2014:131). Berdasarkan referensi tersebut maka dapat disimpulkan pendidikan kewarganegaraan adalah memberikan nilai - nilai cinta tanah air yaitu membentuk sikap sebagai warga negara yang dapat mencerminkan karakter bangsa.

Maka berdasarkan hal tersebut perlu adanya analisis peran guru dalam menumbuhkan sikap cinta tanah air, guru memberikan peran yang penting bagi siswa yaitu memberikan ilmu pengetahuan oleh karena itu guru harus memiliki kualitas diri yang baik. Adapun yang menjadi tolak ukur adalah penulis memberikan solusi berdasarkan buku guru memiliki peranan dalam proses pembelajaran dengan siswa diantaranya : guru sebagai pendidik dan pengajar, guru sebagai mediator dan fasilitator dan guru sebagai model dan teladan (Maimunawati and Alif, 2020:9). Tujuan peran guru pada dasarnya adalah mengarahkan agar siswa mampu tumbuh serta berkembang sesuai dengan potensi, minat dan juga bakatnya siswa dan juga memberikan bimbingan kepada siswa. Dengan memberikan nilai - nilai budaya dapat menumbuhkan sikap cinta tanah air dengan mengenal keberagaman di Indonesia. 
Indonesian Journal of Elementary Education

Vol. 1, No.2, Juli 2021

E-ISSN: 2722-6689

http://jurnal.umt.ac.id/index.php/lJOEE

\section{METODE}

Penelitian ini dilakukan di SDN Tangerang 15 yang berlokasi di Jl. Perintis kemerdekaan No. 39, RT 06/RW 03 Babakan, Kec. Tangerang, Kota Tangerang. Sedangkan waktu penelitian disesuaikan dengan waktu guru. Subjek diambil dari hasil google form yang akan diberika kepada guru kelas III . Penelitian ini mengunakan metode pendekatan kualitatif dengan metode deskriptif, metode deskriptif adalah metode yang menjelaskan atau mendeskripsikan suatu fakta, data, dan objek penelitian secara sistematis dan sesuai dengan situasi alamiah. Menurut Moleong (2017), Penelitian kualitatif adalah penelitian yang bermaksud untuk memahami fenomena tentang apa yang dialami oleh subjek penelitian misalnya perilaku, persepsi, motivasi, tindakan, serta holistic dan dengan cara deskripsi dalam bentuk kata - kata (h.6). Metode kualitatif ditunjukan untuk menghasilkan data deskriptif berupa kata - kata, tulisan atau lisan dari orang - orang dan perilakunya yang diamati. Pengumpulan data bertujuan untuk mengetahui peran guru dalam menumbuhkan sikap cinta tanah air melalui mata pelajaran PKN siswa kelas III SDN Tangerang 15. Teknik pengumpulan pengumpulan data di lakukan melalui metode observasi, wawancara dan dokumentasi.

Analisis data yang digunakan dalam penelitian ini menggunakan model Miles dan Huberman, dengan langkah yang pertama adalah mereduksi data atau memilih hal-hal yang dianggap penting selama penelitian. Langkah yang kedua adalah proses penyajian data dalam penelitian ini dengan membuat teks-teks analisis dari hasil wawancara dan angket yang telah dilakukan. Analisis dilakukan agar peneliti lebih mudah memahami apa yang terjadi dalam proses penelitian. Langkah selanjutnya adalah menarik kesimpulan yang bersifat tetap sehingga dapat menjawab rumusan masalah. Yang pertama adalah mereduksi data : memilih informasi penting sesuai dengan fokus penelitian yang dilakukan yaitu menumbuhkan sikap cinta tanah air dalam mata pelajaran pkn kelas III. Proses ini dilakukan setelah proses pengumpalan data selesai. Yang kedua adalah menyajikan data : tahap penyajian data ini dilakukan dalam uraian kata - kata, hubungan antara fokus penelitiannya. Tahap selanjutnya adalah menarik kesimpulan. Menarik kesimpulan ini berdasarkan apa yang menjadi rumusan masalah yang diangkat dalam penelitian. 
Indonesian Journal of Elementary Education

Vol. 1, No.2, Juli 2021

E-ISSN: 2722-6689

http://jurnal.umt.ac.id/index.php/IJOEE

\section{Hasil Dan Pembahasan}

\section{Hasil}

Guru adalah seseorang yang melakukan kegiatan pembelajaran dengan formal maupun informal untuk menguasai aspek-aspek kognitif siswa. Cara guru mengajar di kelas merupakan keberhasilan siswa dalam mencapai nilai yang sesuai dengan ke inginan, guru juga harus memberikan contoh yang baik terhadap siswa. Peran guru dalam menumbuhkan sikap cinta tanah air melalui mata pelajaran PKN siswa kelas III. Hasil penelitian ini berdasarkan data yang akan menjawab rumusan masalah dari penelitian. Data penelitian di peroleh dari wawancara yang dilakukan peneliti melalui google form. Kemudian data penelitian di analisis sehingga dapat memperoleh kesimpulan yang akan menjawab tujuan dari penelitian. Ada beberapa peranan guru dalam melakukan kegiatan proses pembelajaran dengan siswa diantaranya :

Guru berperan sebagai pendidik dan pengajar, sebagai guru harus dapat membimbing dan juga menumbuhkan sikap yang baik kepada siswa. peran guru sebagai pendidik dan pengajar adalah satu kesatuan yang tidak bisa dipisahkan. Guru harus bisa menjelaskan materi yang diajarkan kepada siswa dengan cara yang mudah agar siswa mengerti dengan apa yang dijelaskan oleh guru. Guru harus mampu mengembangkan kemampuan siswa dengan baik yaitu membangun etika dan kesopanan kepada siswa agar dapat tumbuh di masa depan.

Berdasarkan hasil google form yang peneliti berikan kepada guru kelas III yang pertama guru berperan sebagai pendidik dan pengajar dalam menumbuhkan sikap cinta tanah air, dalam membuat perencanaan pembelajaran sudah sesuai dengan K1 yang berhubungan dengan sila pertama Ketuhanan yang Maha Esa diantara kegiatannya yaitu dengan berdoa dan bersyukur. Pengembangan kurikulum juga sudah berorintasi pada sikap pancasila dengan kurikulum 13 sudah mencakup nilai pancasila. Pelaksanaan upacara disekolah selalu dilakukan karena dengan upacara dapat menumbuhkan nilai pancasila dan membiasakan sikap disiplin kepada siswa. Hambatan dalam proses menumbukan sikap cinta tanah air salah satunya dalam kegiatan upacara masih ada siswa yang belum dispilin contohnya bercanda maupun sikap yang belum sempurna. Cara guru dalam mengoptimalkan sikap pancasila dalam pembelajaran pkn dengan menerapkan 
Indonesian Journal of Elementary Education

Vol. 1, No.2, Juli 2021

E-ISSN: 2722-6689

http://jurnal.umt.ac.id/index.php/IJOEE

disekolah cara 3s yaitu salam, sapa, senyum. Guru dalam memahami karakteristik sikap pancasila siswa yaitu dengan cara menilai sikap siswa dikeseharian contohnya menghormati guru ataupun bergaul dengan temannya. Dalam mengukur perkembangan siswa menumbuhkan sikap pancasila dengan adanya perubahan sikap dan perilaku siswa disekolah contohnya belajar dengan baik, mencintai keberagaman di Indonesia. Pembiasaan sikap cinta tanah air dilingkungan sekolah biasanya siswa sebelum memulai pelajaran membacakan visi dan misi sekolah serta menyanyikan lagu wajib nasional bersama - sama. Mengetahui tingkat pemahaman siswa dalam sikap pancasila terhadap pembelajaran pkn yaitu dengan menilai sikap pengetahuan dan juga keterampilan siswa dikelas secara objektif. Model pembelajaran guru yang digunakan dalam menumbuhkan sikap cinta tanah air dengan cara pembelajaran yang bervariasi dan juga memberikan pembelajaran yang berkarakter.

Yang kedua guru berperan sebagai sumber belajar dan fasilitator, sebagai guru harus memiliki strategi yang tepat dalam mengembangkan sikap cinta tanah air yaitu dengan memberikan contoh sikap dan perilaku siswa yang positif serta mencintai produk dalam negeri. Cara guru dalam memberikan pembelajaran sikap cinta tanah air dikelas dengan memberikan pembelajaran yang berhubungan dengan cinta tanah air contohnya dalam pembelajaran sejarah dan pembiasaan sikap baik dan sopan yang dilakukan siswa. Guru dalam memberikan pembelajaran yang kreatif agar dapat menumbuhkan sikap cinta tanah air pada pembelajaran pkn diantaranya dengan melakukan kegiatan gotong royong dan membersihkan lingkungan di sekolah. Media interaktif yang digunakan guru dalam proses pembelajaran pkn pada mata pelajaran pkn melalui media yang ada dilingkungan sekitar, teman sekelas dan juga pengalaman siswa, bisa juga memakai video animasi yang menampilkan tentang sikap cinta tanah air. Pendekatan guru yang dilakukan dalam menumbuhkan sikap pancasila melalui pendekatan yang kreatif, inovatif dan juga menyenangkan. Sumber belajar guru dalam menumbuhkan sikap cinta tanah air melalui buku siswa, pegangan guru, lks dan buku sumber yang berhubungan kegiatan pembelajaran. Guru sudah memberikan materi yang baik dan sesuai kepada siswa dalam menumbuhkan sikap pancasila. Media yang efektif untuk memberikan sikap cinta tanah air dalam pembelajaran pkn yaitu dengan pengalaman langsung dan memberikan contoh 
Indonesian Journal of Elementary Education

Vol. 1, No.2, Juli 2021

E-ISSN: 2722-6689

http://jurnal.umt.ac.id/index.php/lJOEE

positif kepada siswa. Proses belajar mengajar yang dilakukan guru dalam menumbuhkan sikap cinta tanah air melalui pembelajaran yang kreatif, efektif dan juga efisien. Ketrampilan yang harus dikuasai siswa dalam pembelajaran pkn dengan ketrampilan sikap dan pembelajaran yang berkarakter.

Yang ketiga guru berperan sebagai model dan teladan sebagai guru harus memiliki sikap dan perilaku yang mencerminkan pancasila diantaranya sikap yang religious, sopan, dan mau di kritik kalau ada salah mampu beratanggung jawab atas kesalahannya. Guru dalam memberikan rasa menghargai pada pembelajaran pkn dengan cara memberikan penilaian yang positif kepada siswa. Guru dalam memberikan rasa kebanggaan terhadap cinta tanah air kepada siswa yaitu mencintai bangsa Indonesia dan mencintai produk dalam negeri. Cara guru dalam menjaga sikap cinta pancasila kepada siswa melalui contoh yang baik dan memberikan hal-hal yang positif. Guru sudah menjaga toleransi terhadap guru yang lain karena sudah menjadi keluarga PGRI. Guru sudah memiliki sikap sabar karena kesabaran adalah modal utama dalam proses kegiatan belajar mengajar dan sikap rela berkorban sudah seharusnya sebagai abdi negara. Guru sudah membimbing siswa dalam menggunakan bahasa Indonesia yang baik dan benar sesuai dengan Eyd. Disinih guru sudah melestarikan budaya Indonesia kepada siswa melalui pentas seni yang menampilkan hasil karya tarian tradisional yang diadakan oleh sekolah. Cara guru dalam memberikan apresiasi pada siswa jika melakukan pembelajaran dengan baik yaitu memberikan penghargaan berupa piagam maupun piala bisa juga dengan nilai dan cindra mata. Guru sudah menerapkan sikap cinta tanah air dalam kehidupan sehari-hari dengan menggunakan pakaian batik pada hari tertentu.

\section{Pembahasan}

Berdasarkan hasil perolehan data yang sudah diambil dari responden, bisa disimpulkan bahwa analisis peran guru dalam menumbuhkan sikap cinta tanah air pada mata pelajaran pkn di SDN Tangerang 15 dengan memberikan contoh yang baik dan mencintai tanah air dalam kehidupan sehari-hari. Guru selalu mengingatkan bersikap jujur dan menghargai berbedaan, toleransi dan displin di sekolah maupun diluar sekolah. Guru juga membimbing sesuai dengan minat dan potensi yang dimiliki oleh siswa. Hubungan guru dan siswa harus terjalin dengan baik untuk dapat memberikan motivasi dan arahan 
Indonesian Journal of Elementary Education

Vol. 1, No.2, Juli 2021

E-ISSN: 2722-6689

http://jurnal.umt.ac.id/index.php/IJOEE

yang sesuai. Penanaman cinta tanah air dilakukan di sekolah yang lebih efektif karena dapat membentuk semangat bagi siswa yang akan menentukan masa depan. Dalam pembelajaran pendidikan kewarganegaraan siswa dapat mencintai tanah air dengan keberagaman yang ada di Indonesia. Rasa cinta tanah air merupakan memperkuat persatuan dan kesatuan bangsa dalam kehidupan sehari-hari seperti dalam lingkungan sekolah, keluarga maupun masyarakat. Informasi yang baik juga perlu dikembangkan dengan baik agar semangat cinta tanah air tidak luntur.

\section{Penutup}

\section{Kesimpulan}

Peran guru dalam menumbuhkan sikap cinta tanah air pada mata pelajaran pkn siswa kelas III di SDN Tangerang 15, membentuk sikap cinta tanah air dengan melakukan bebrapa hal yaitu : pertama guru berperan sebagai pendidik dan pengajar, mengajarkan siswa betapa pentingnya cinta tanah air terutama dalam pembelajaran pkn. Menanamkan nilai-nilai yang terdapat di dalam materi menjadikan bagian dari kehidupan sehari-hari. kedua guru berperan sebagai sumber belajar dan fasilitator, guru harus memiliki sumber belajar yang baik dan menguasai materi pelajaran dengan penguasaan materi yang baik siswa akan semangat untuk mengikuti pembelajaran di kelas. Guru juga memberikan media interaktif agar siswa dapat memahami dan memiliki sikap cinta tanah air dalam kehidupan sehaihari. ketiga guru berperan sebagai model dan teladan, guru harus memberikan contoh yang terhadap siswa salah satunya religious, sopan dan mau untuk dikritik dengan begitu siswa akan memahami sikap cinta tanah air. Guru juga selalu membimbing siswa untuk mencapai tujuan pembelajaran yang baik. Memakai baju batik pada hari tertentu itu salah satu membentuk sikap cinta tanah air.

\section{Saran}

Dalam menanamkan sikap cinta tanah air peran orang tua juga sangat penting, guru memiliki tanggung jawab untuk keberhasilan siswa maka jika orang tua dan guru membagi tugas dalam menumbuhkan sikap cinta tanah air, maka siswa akan memiliki sikap cinta tanah air yang tinggi dilingkungan sekolah maupun masyarakat. 
Indonesian Journal of Elementary Education

Vol. 1, No.2, Juli 2021

E-ISSN: 2722-6689

http://jurnal.umt.ac.id/index.php/IJOEE

\section{DAFTAR PUSTAKA}

Diana Sari. 2017. “Cinta Tanah Air Dan Salafus Shalih.” Prosiding Konferensi Nasional Kewarganegaraan p-ISSN 259(November):64-72.

Ismawati. 2015. "PERAN GURU PKn DALAM MEMBENTUK SIKAP CINTA TANAH AIR SISWA DI SMA NEGERI 1 MOJOSARI KABUPATEN MOJOKERTO.” Jurnal Kajian Moral Dan Kewarganegaraan 2:887-91.

Komalasari, mahilda dea, and ahmad mabruri Wihaskoro. 2018. "Multimedia Interaktif Bermuatan Keanekaragaman Budaya Indonesia Pada Pembelajaran Tematik Untuk Meningkatkan Rasa Cinta Tanah Air Siswa Sekolah Dasar." Elementary School 5:121.

Kusuma, Wijaya. 2017. Cinta Tanah Air. Yogyakarta : Familia.

Maimunawati, Siti, and Muhammad Alif. 2020. "Peran Guru, Orang Tua, Metode Dan Media Pembelajaran.Pdf." Banten : 3M Media karya serang.

Masoyang, Tilka, Bonifasius Saneba, and Anthonius Palimbong. 2014. "Meningkatkan Hasil Belajar Pada Pembelajaran PKn Melalui Kooperatif Tipe Student Teams Achievement Division ( STAD ) Di Kelas V SDN Inpres Popisi Kecamatan Peling Tengah." Kreatif Tadulako Online 2(2):128-41.

Moleong. n.d. "Metodologi Penelitian Kualitatif_Moleong.Pdf." Bandung : PT Remaja Rosdakarya Offset.

Ulifah, Desi, and I. Made Suwansa. 2017. "Strategi Sekolah Dalam Menanamkan Sikap Cinta Tanah Air Pada Peserta Didik Di SMPN 1 Tarik Kabupaten Sidoarjo.” Kajian Moral Dan Kewarganegaraan 08(03):871-86. 